\title{
Escherichia coli na suinocultura. Aspectos clínicos. Uma Revisão
}

\author{
Caio Vitor Oliveira Silva*1, Amanda Medeiros Araujo de Oliveira ${ }^{2}$, Pablo Perón Nobrega Bezerra ${ }^{3}$, \\ Jose Nailton Bezerra Evangelista ${ }^{3}$
}

${ }^{1}$ Grupo de pesquisa em suinocultura, Universidade Estadual do Ceará, Fortaleza, Ceará, Brasil. Autor para correspondência. E-mail: * caiovitor94@veterinario.med.br

${ }^{2}$ Faculdade de Medicina Veterinária, Universidade Estadual do Ceará, Fortaleza, Ceará, Brasil

${ }^{3}$ Faculdade de Medicina Veterinária, Universidade Estadual do Ceará, Fortaleza, Ceará, Brasil

RESUMO: A Escherichia coli é um dos patógenos de maior potencial de contaminação nas granjas de suínos, principalmente devido a sua resistência a drogas antimicrobianas. Sendo a colibacilose uma das enfermidades entérica de maior risco na suinocultura é de fundamental o conhecimento sobre a epidemiologia e patogenia da infecção por E.coli, além de abordagem sobre aspectos relativos ao controle e ao tratamento.

Palavras chave: Escherichia coli, colibacilose; criação de suínos

ABSTRACT: Escherichia coli is one of the pathogens of greatest potential for contamination on swine farms, mainly due to its resistance to antimicrobial drugs. With an enteric colibacillosis illness of greater potential in pigs. therefore fundamental knowledge on the epidemiology and pathogenesis of infection with E.coli. In addition to addressing issues related to the control and treatment.

Kewords: Escherichia coli, colibacilose; criação de suínos

Autor para correspondência. E-mail: * caiovitor94@ veterinario.med.br

Recebido em 10/03/2015; Aceito em 15/06/2015

http://dx.doi.org/10.5935/1981-2965.20150028

\section{INTRODUÇÃO}

No Brasil, a partir da década de 70, a criação de suínos passou por diversas modificações. Por meio da intensificação na produção, de melhorias genéticas e nutricionais, uma melhor produtividade foi obtida. Porém, essa intensificação predispôs os animais ao estresse, trazendo um maior risco de aquisição de doenças. Mesmo com os esforços para controle das enfermidades gastrointestinais, estas são responsáveis por inúmeras perdas na produção de suínos. As diarréias são 
principalmente observadas em neonatos e animais após o desmame. Enquanto as perdas econômicas associadas à mortalidade são evidentes, a redução no desempenho nem sempre é detectada pelo produtor, ocasionando prejuízos consideráveis (COOPER, 2000).

A suinocultura moderna tem propiciado a obtenção de índices produtivos positivos, entretanto tem predisposto os suínos a um grande número de doenças. A ocorrência dessas enfermidades estimulou o uso indiscriminado das drogas antimicrobianas na prevenção de infecções. A Escherichia coli é um dos principais patógenos da suinocultura e se caracteriza pela alta resistência aos agentes antimicrobianos. A habilidade deste patógeno na transmissão horizontal da resistência aos antimicrobianos decorre de vários mecanismos genéticos e possui sérias implicações à saúde pública. Dentre os problemas associados à disseminação da resistência múltipla aos antimicrobianos, podemos citar a contaminação do homem e dos animais por bactérias patogênicas de difícil controle terapêutico, principalmente por meio dos alimentos e de ambiente contaminados. Esta revisão tem como objetivo abordar aspectos relevantes de E. coli relativos ao seu potencial patogênico em suínos e à sua resistência às drogas antimicrobianas. Além disso, também apresenta algumas das alternativas aos usos desses fármacos na suinocultura.

\section{Epidemiologia}

A colibacilose é a enfermidade entérica de maior impacto na suinocultura, especialmente em animais neonatos e no pósdesmame. Essa doença pode ser provocada por cepas enterotoxigênicas de E. coli. Para o desenvolvimento da enfermidade é necessária a adesão da bactéria à mucosa intestinal e a produção de uma ou mais enterotoxinas termolábeis, e termoestáveis, que levam ao desenvolvimento de diarréia e desidratação, podendo resultar na morte dos animais (HENTON; HUNTER, 1994; GYLES ; FAIRBROTHER, 2004). A maior prevalência da infecção e morte em suínos ocorre no período de 12 horas a quatro dias após o nascimento (COOPER , 2000).

A colibacilose neonatal se dá pela ingestão de bactérias de origem materna e ambiental, ausência das defesas naturais, como microbiota do intestino e barreira gástrica, presença de receptores para fímbrias nos recémnascidos e a alta susceptibilidade dos animais às enterotoxinas produzidas por E. coli (GYLES; FAIRBROTHER, 2004). Associados a estes fatores, a inadequada ingestão de colostro pelos leitões é considerada como um dos principais fatores predisponentes (HENTON; HUNTER, 1994).

$\mathrm{O}$ estresse e a redução nos níveis de anticorpos recebidos passivamente desempenham um importante papel na infecção por ETEC em suínos desmamados. O desmame altera a fisiologia dos animais e induz a uma 
elevação do $\mathrm{pH}$ estomacal, provocando redução na atividade bactericida gástrica (HENTON; HUNTER, 1994). A diarréia pós-desmame está associada à elevação do número de $E$. coli hemolíticas em relação às não hemolíticas no trato gastrointestinal; decorrente principalmente da troca da dieta dos leitões (COOPER, 2000; GYLES; FAIRBROTHER, 2004). A importância clínica das E. coli enteropatogênicas tem sido relatada, além de suínos, em outras espécies animais, como ruminantes, cães, macacos e no próprio homem (TENG et al ., 2004). Contudo, poucos são os dados relativos à prevalência da infecção por esse patotipo nos suínos, em especial no Brasil. Esta bactéria também pode determinar um sério impacto à suinocultura por estar envolvida no desenvolvimento de diarréias neonatais e pósdesmame associadas a má absorção de nutrientes .

\section{Patogenia}

As cepas enterotoxigênicas de E. coli aderem-se ao intestino delgado e grosso dos animais, sendo o duodeno e o ceco os locais de maior colonização (BERTSCHINGER ; FAIRBROTHER, 1999, 2000). A lesão produzida é denominada attaching effacing. Neste processo, os enterócitos são degenerados e uma leve inflamação da lâmina própria pode ser observada, principalmente, no íleo. A lesão de attaching effacing é caracterizada pela adesão de uma proteína localizada na superfície da bactéria, denominada intimina, à superfície do enterócito. A intimina provoca um rearranjo no citoesqueleto da célula, particularmente nos filamentos de actina, levando a um encurtamento das microvilosidades dos enterócitos e à formação de um pedestal onde a bactéria se aloja. Com isto, ocorre a perda da capacidade absortiva do epitélio intestinal (GYLES; FAIRBROTHER, 2004). Outra importante enfermidade, ocasionada por E.coli verotoxigênicas em leitões recém-desmamados, é a doença do edema. Estas E. coli possuem uma alta relação com as cepas enterotoxigênicas de E. coli. As duas possuem ilha de patogenicidade denominada LEE (lócus enterocite effacement), entretanto a STEC produz shigatoxinas, sendo a STx2e considerada importante para suínos. Esta toxina é encontrada como parte do genoma de um fago temperado, o qual se integra ao genoma da célula hospedeira, sendo encontrado em diversos sorotipos de $E$. coli e em outros membros da família Enterobacteriaceae (TOTH et al., 2003). Depois de uma infecção inicial do trato intestinal, esses microorganismos se aderem e se multiplicam no interior do intestino delgado (HENTON; HUNTER, 1994; MOXLEY, 2000). A fímbria F18a/b está relacionada à adesão de cepas causadoras da doença do edema. Durante a multiplicação da bactéria, a shiga toxina é produzida e absorvida pela circulação sistêmica, onde induz a inativação da síntese proteica em células do endotélio vascular do intestino delgado, em tecidos subcutâneos e no encéfalo. A destruição das células endoteliais leva ao aparecimento do edema e de sinais neurotóxicos 
característicos da doença (HENTON; HUNTER, 1994). A suscetibilidade dos animais à infecção por EHEC varia, sendo relacionada a um mecanismo genético. A resistência natural à doença do edema ocorre pela não-expressão de receptores $(\mathrm{F} 18 \mathrm{a} / \mathrm{b})$ no intestino dos animais (MOXLEY, 2000).

Em relação às Infecções do Trato Urinário (ITU), sabe-se que as fêmeas estão mais sujeitas a essas infecções devido a uma série de diferenças anatômicas e fisiológicas. As infecções do trato urinário dos suínos influenciam negativamente seus índices de produtividade devido aos prejuízos associados às doenças puerperais, infertilidade, gastos com medicamentos, redução de peso dos leitões e mortalidade. As E. coli uropatogênicas são a principal causa de infecção do trato urinário em mulheres, e são também associadas à morte de fêmeas suínas. Segundo BRITO et al. (2004), pode ocorrer o isolamento de E. coli em urina de fêmeas clinicamente sadias, sendo, portanto, consideradas portadoras assintomáticas.

\section{Diagnóstico}

Conforme HENTON; HUNTER (1994), a maioria das cepas patogênicas de E. coli isoladas de suínos é hemolítica. No entanto, esta característica não é observada em outras espécies domésticas. Na maior parte dos casos, somente o isolamento de E. coli a partir de amostras de fezes e conteúdo intestinal pode não ser suficiente para o diagnóstico da enfermidade.
Nestes casos, é necessária a biotipificação de fímbrias e toxinas. A biotipificação dos isolados pode ser realizada por soro-aglutinação, ELISA, imunofluorescência e PCR (genotipificação).

\section{Controle e tratamento}

A E. coli é uma das espécies nas quais cepas multirresistentes aos antimicrobianos têm emergido rapidamente. Estudos demonstraram que existe uma grande diferença na resistência aos antimicrobianos entre os isolados de cepas enterotoxigênicas de $E$. coli e outros comensais. Estudo realizado na Suíça com E. coli alertou para resistência às tetraciclinas, sulfonamidas e estreptomicina, usadas indiscriminadamente na alimentação de suínos no país (STEPHAN ; SCHUMACHER, 2001). Mesmos achados foram obtidos em amostras de animais submetidos ao abate em Portugal (PENA et al., 2004).

DUNLOP et al. (1999), nos EUA, verificaram resistência à tetraciclina em $71 \%$ de seus isolados. Porém, este índice foi considerado baixo, tendo em vista pesquisas em outros países onde esta droga é adicionada à ração dos animais.

E. coli é uma das principais espécies onde plasmídeos contendo genes envolvidos no processo de resistência múltipla aos antimicrobianos vêm sendo descritos. Essa característica está relacionada a sua grande distribuição ambiental e propensão a albergar elementos genéticos móveis, em especial os plasmídeos. A conjugação, transposição e 
recombinação são amplamente incriminadas com a evolução da resistência bacteriana aos antimicrobianos. Eventos de transposição e integração são importantes mediadores da resistência múltipla às drogas antimicrobianas dentro da família Enterobacteriaceae (SHERLEY et al ., 2004).

uso de antimicrobianos não pode ser considerado a única pressão de seleção para bactérias resistentes. Os plasmídeos podem carrear genes com diferentes funções, tais como: fatores de virulência, adesinas, toxinas, resistência a metais pesados e genes de metabolismo de substratos incomuns (SHERLEY et al ., 2004). Desta

forma, desinfetantes e suplementos alimentares podem apresentar uma importante força de seleção para bactérias resistentes numa criação de suínos. Também a resistência a um antimicrobiano pode ajudar na co-seleção de resistência à outras drogas.

Em muitos casos, a resistência a uma determinada droga pode se estender a outras ligadas geneticamente. Como exemplo, temos a gentamicina, amplamente usada na suinocultura, cujo gene de resistência está localizado num plasmídeo, que também codifica caráter de resistência para tetraciclina, sulfonamidas e penicilinas.

Após o uso de uma droga antimicrobiana, principalmente as de amplo espectro, pode-se observar a elevação do percentual de cepas resistentes entre bactérias patogênicas e comensais (WHITE et al., 2006).
Segundo DUNLOP et al . (1999), a redução no tratamento de animais com grupos de antimicrobianos de largo espectro pode auxiliar na redução da prevalência de $E$. coli resistentes em suínos. Porém, trabalho recente apontou que os genes e elementos móveis responsáveis pela resistência, quando adquiridos, representam um custo muito baixo à bactéria.

Desta

forma, a $E$. coli tende a mantê-los, indicando que a redução na resistência aos antimicrobianos pela remoção na pressão de seleção, ou seja, na alimentação dos animais com antibióticos, pode, no mínimo, ser um processo muito lento (ENNE et al., 2005).

\section{Coclusão}

Assim, é importante a manutenção de investimentos no sentido de conservar a sanidade dos animais, reduzindo a necessidade de antibioticoterapia, através de um manejo sanitário adequado (tudo dentro, tudo fora) e eficiente de forma que seja minimizada a ação destes patógenos.

\section{REFERÊNCIAS BIBLIOGRÁFICAS}

BERSOT, L dos S.; OLIVEIRA, L.A.T.; FRANCO, R.M.; CARVALHO, J.C.A.P. Avaliação bacateriológica de carne suína (carré $=$ Longissimus dorsi + base óssea) comercializada em Niterói e São Gonçalo - R.J. Brasil. Revista Brasileira de Ciências Veterinárias, v.5, n.1, p.3-7, 1998.

BARCELLOS D. \& SOBESTIANSKY J. Uso de Antimicrobianos em Suinocultura. Goiânia. 107p. 1998. 
MOTA R.A., SILVA K.P.C., FREITAS M.F.L., PORTO W.J.N. \& SILVA L.B.G. Utilização indiscriminada de antimicrobianos e sua contribuição a multirresistência bacteriana. Braz. J. Vet. Res. Anim. Sci. 42:465-470. 2005.

SCHMIDT, V.; CARDOSO, M.R.I. Sobrevivência e perfil de resistência aos antimicrobianos de Salmonella sp. isoladas em um sistema de tratamento de dejetos suínos. Ciência Rural , v.33, n.5, p.881-888, 2003.

SOBESTIANSKY, J.; MORES, N.; VIEIRA, R.A.B. Infecções urinárias na fêmea suína. Concórdia, SC: EMBRAPA-CNPSA, 1991. 49p. (Circular Técnica 11).

SOBESTIANSKY, J. et al.; Clínica e Patologia

Suína. Goiânia, GO: Art 3, 1999

SILVA, C.A.; BRITO, B.G.; MORES, N.

Fatores de risco responsáveis pelo aparecimento de diarréias pré-desmame em granjas suinícolas no norte do Paraná. In: CONGRESSO BRASILEIRO DE VETERINÁRIOS ESPECIALISTAS EM SUÍNOS, VII, 1995, Blumenau-SC. Anais [S. n.], 1995. p. 85.

STEPHAN, R SCHUMACER. Resistance patterns of non-O157 Shiga toxin-producing Escherichia coli (STEC) strains isolated from animals, food and asymptomatic human carriers in Switzerland. Letters in Applied Microbiology. Zurich, Switzerland p.114-117.v37.2000. 